\title{
Central nuclear counts in muscle fibres before and during treatment in hypothyroid myopathy
}

\author{
R. O. MCKERAN 1,4 , P. WARD 2 , G. SLAVIN ${ }^{2,3}$, AND E. A. PAUL
}

From the Divisions of Inherited Metabolic Diseases ${ }^{1}$ and Cell Pathology ${ }^{2}$, and the Department of Histopathology ${ }^{3}$, Clinical Research Centre, and Northwick Park Hospital, Harrow, University College Hospital London ${ }^{4}$, and the Institute of Neurology, London ${ }^{5}$, UK

SUMMARY Serial percutaneous needle muscle biopsies of vastus lateralis were studied in 10 patients who had varying degrees of hypothyroid myopathy. The biopsies were taken before and during treatment with L-thyroxine. Before treatment the most severely clinically affected patients showed type II muscle fibre atrophy and loss, together with increased central nuclear counts preferentially affecting the type II muscle fibre. Both the type II muscle fibre atrophy and loss and the increased central nuclear counts tended to return towards normal values during treatment with L-thyroxine. The severity of myopathic symptoms before and during treatment correlated with the biochemical evidence of hypothyroidism, a type II fibre atrophy, and increased central nuclear counts. The severity of myopathic signs before and during treatment was correlated with both a type II fibre atrophy and loss and increased central nuclear counts. There was no evidence that the myopathic signs before and during treatment were related to the biochemical parameters of hypothyroidism, except the level of thyroid stimulating hormone.

It is suggested that sequential studies of muscle fibre percentages, diameters, and central nuclear counts may provide an additional method of assessing the response to treatment in hypothyroid and possibly other types of myopathy. When increased central nuclear counts are confined to a specific muscle fibre type, this may suggest a hitherto unsuspected specificity of muscle fibre damage.

Central migration of muscle nuclei, from their normal position beneath the sarcolemmal membrane, in more than $3 \%$ of muscle fibres cut in cross section is regarded as abnormal. This increase in central nuclei is seen in both a wide variety of neuromuscular disorders (Greenfield et al., 1957; Dubowitz and Brooke, 1973) and in normal muscles near tendon origins and in extraocular muscles (Adams et al., 1953). A practical application for central nuclear counts as an aid to diagnosis has recently been found. In the younger reproductive age group, central nuclear counts were found to be significantly higher for carriers of Duchenne muscular dystrophy than for normals (Baker et al., 1971).

In a study of hypothyroid myopathy, a type II fibre atrophy and loss was found, which was proportional to the degree of hypothyroidism as judged clinically and biochemically (McKeran et al., 1975). Improvement in the symptoms and signs of myopathy after treatment with L-thyroxine was closely related to the return of the type II fibre atrophy and

Received for publication 26 September 1978 loss towards normal values. In this paper we investigate the changes in central nuclear counts in hypothyroid myopathy in an attempt to establish how they relate to both clinical improvement in the myopathy and the return of the type II fibre atrophy and loss toward normal values. Central nuclear counts were measured separately for type I and type II muscle fibres in both patients and controls.

\section{Patients and methods}

Ten hypothyroid patients were studied by serial percutaneous needle biopsies of vastus lateralis. All of these patients had biopsies before treatment with L-thyroxine, and six of them had further biopsies over periods of up to 24 months of treatment. The evidence for a myopathy ranged from elevation of serum creatine phosphokinase (CPK, adenosine 5 'triphosphate creatine phosphotransferase, EC 2.7.3.2) alone, to a gross proximal muscle weakness with wasting. There was no evidence of denervation on light microscopy of a proximal clinically affected muscle. Electromyography was performed on the 
patients, with concentric needle sampling of the upper limb proximal and distal muscles. There was no spontaneous activity, and the interference pattern was not reduced on maximal contraction. Conduction velocities and sensory action potentials were within normal limits for the patients' ages. The main clinical features of the patients together with their biochemistry and the timing of muscle biopsies in relation to the duration of treatment are shown (Table 1). Healthy male and female volunteers served as controls.

Percutaneous needle biopsies of vastus lateralis were performed using a modified Bergström needle under local analgesia (5-10 $\mathrm{ml}$ of $1 \%$ lignocaine) through a $5 \mathrm{~mm}$ incision in the skin and deep fascia (Edwards, 1971). Muscle specimens (30-60 mg wet weight) were allowed to relax in air at room temperature for $15 \mathrm{~min}$. They were then snap frozen in isopentane, cooled in liquid nitrogen, orientated for cross sections, cut on a cryostat, and stained for haematoxylin and eosin and myosin-ATPase, $\mathrm{pH} 9.4$ (Padykula and Herman, 1955), then counterstained with methyl green to demonstrate the nuclei. The numbers of central nuclei/100 fibres were counted on three sections stained by haematoxylin and eosin, and the mean value of the three sections was calculated. Similarly, the number of central nuclei in 100 type I fibres was counted on three sections stained for ATPase and methyl green, and the mean was calculated. The number of central nuclei in 100 type II fibres was derived from the number in 100 type I fibres, the percentage of type I to type II fibres, and the number of central nuclei/100 fibres. This was necessary because the nuclei were not reliably demonstrated in all ATPase, methyl green stained type II fibres (see Calculation). From photographic prints of ATPase stained sections (enlarged to a $\times 250$ magnification) the proportion of type $I$ and type II fibres was determined, and the diameters of 200 fibres were measured as the maximum distance across the lesser aspect of the muscle fibre (Brooke and Engel, 1969a, b).

\section{Calculation}

Derivation of the number of central nuclei in 100 type II fibres:

\begin{tabular}{|c|c|c|c|c|}
\hline $\begin{array}{l}\text { No. of central } \\
\text { nuclei in type I } \\
\text { fibres/100 fibres }\end{array}$ & $=\mathrm{x}=$ & $\begin{array}{l}\text { No. of central } \\
\text { nuclei per } 100 \\
\text { type I fibres }\end{array}$ & $x$ & $\begin{array}{l}\begin{array}{l}\text { Percentage of } \\
\text { type I fibres }\end{array} \\
100\end{array}$ \\
\hline $\begin{array}{l}\text { No. of central } \\
\text { nuclei in type II } \\
\text { fibres } / 100 \text { fibres }\end{array}$ & $=\mathbf{y}=$ & $\begin{array}{l}\text { No. of central } \\
\text { nuclei/100 } \\
\text { fibres }\end{array}$ & $-x$ & \\
\hline $\begin{array}{l}\text { No. of central } \\
\text { nuclei in } 100 \\
\text { type II fibres }\end{array}$ & $=y \times$ & $\begin{array}{l}\frac{100}{\text { Percentage of }} \\
\text { type II fibres }\end{array}$ & & \\
\hline
\end{tabular}

\section{Results}

The main clinical features, biochemistry, timing of muscle biopsies, percentage of type I and type II fibres, median diameters of type I and type II fibres, and central nuclear counts per 100 fibres and per 100 type I and type II fibres before and during treatment for each patient are shown in Table 1 . The table also includes means and standard errors for each variable for the controls.

Kendall rank correlation coefficients were calculated between the severity of myopathic symptoms and signs and the other variables measured (Table 2). The myopathic symptoms before and during treatment correlated with the thyroid stimulating hormone (TSH), $\mathrm{T}_{3}$ uptake, $\mathrm{T}_{4}, \mathrm{CPK}$, median diameter of type I and II fibres, and increase in central nuclear counts per 100 fibres and per 100 type I fibres. The myopathic signs before and during treatment did not correlate with the biochemical measures of hypothyroidism except the TSH. However, they were related to the type II fibre atrophy and loss and the increase in central nuclear counts per 100 fibres and per 100 type I and II fibres. The increase in type II central nuclear counts tended to be larger than the increases in type I central nuclear counts (Table 1). Serum CPK values returned to normal within one month of treatment in all patients except patient 5 , who had failed to take thyroxine regularly. The serum CPK had returned to normal in patients 1 and 2 when they still had a significant clinical myopathy (Table 1).

\section{Discussion}

Increased numbers of central nuclei in muscle fibres have been reported during myogenesis in the myotubes, in a congenital myopathy associated with type I fibre atrophy (Engel et al., 1968; Bethlem et al., 1969), in brain-damaged children (Fenichel, 1969), and in a slowly progressive myopathy beginning in early life (Spiro et al., 1966; Sher et al., 1967). It is also a feature of dystrophia myotonica (Adams et al., 1953-where it is associated with type I fibre atrophy) muscle fibre regeneration, denervation atrophy in chronic peripheral neuropathies, muscular dystrophy, polymyositis (Brooke and Engel, 1966), and metabolic myopathies (Ramsay, 1974). The general factors that have been identified as being associated with central migration of nuclei therefore included presumed delayed maturation of muscle cells with type I atrophy, congenital and inherited disorders of muscle metabolism, loss of trophic nervous influence, inflammation, and an altered hormonal environment.

Hypothyroid myopathy is of interest because it is 
Table 1 Main clinical features, biochemistry, timing of muscle biopsies, percentage, median diameters, and central nuclear counts in type I and type II muscle fibres in 10 patients with varying degrees of hypothyroid myopathy, with control values

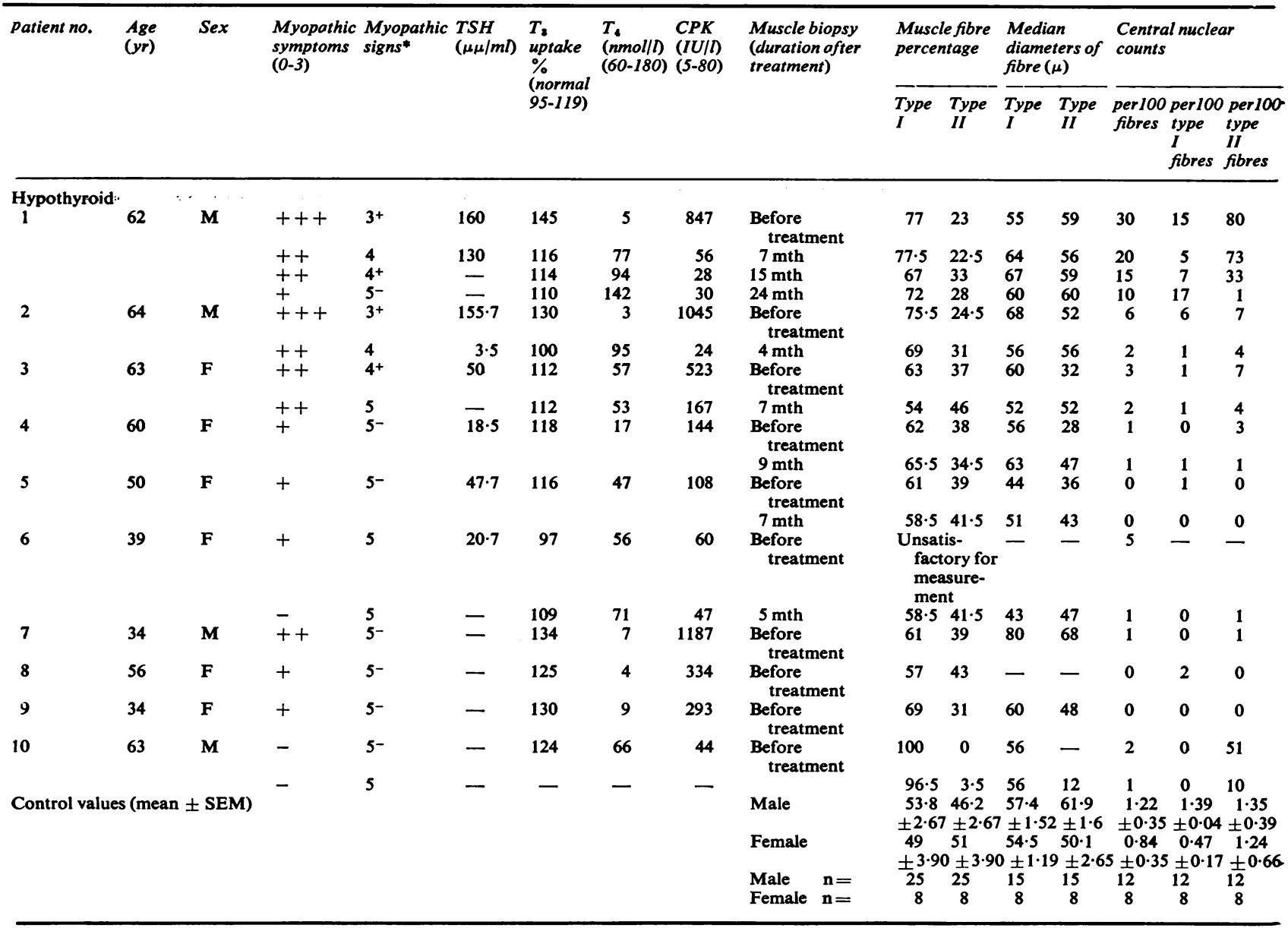

* Medical Research Council Scale of Muscle Weakness (1974).

+ slight, ++ moderate, +++ severe symptoms of a proximal myopathy.

Table 2 Kendall rank correlation coefficients between clinical symptoms and signs of hypothyroid myopathy and biochemical parameters of hypothyroidism, muscle fibre percentages, median diameters, and central nuclear counts

\begin{tabular}{|c|c|c|c|c|c|c|c|c|c|c|c|c|}
\hline & & \multirow[t]{2}{*}{$T S H$} & \multirow[t]{2}{*}{$\begin{array}{l}T_{8} \\
\text { uptake }\end{array}$} & \multirow[t]{2}{*}{$T_{4}$} & \multirow[t]{2}{*}{$C P K$} & \multicolumn{2}{|c|}{$\begin{array}{l}\text { Muscle fibre } \\
\text { percentages }\end{array}$} & \multicolumn{2}{|c|}{$\begin{array}{l}\text { Median diameters } \\
\text { of fibres }\end{array}$} & \multicolumn{3}{|c|}{ Central nuclear counts } \\
\hline & & & & & & Type I & Type II & Type I & Type II & $\begin{array}{l}\text { per } 100 \\
\text { fibres }\end{array}$ & $\begin{array}{l}\text { per } 100 \\
\text { type I } \\
\text { fibres }\end{array}$ & $\begin{array}{l}\text { per } 100 \\
\text { type II } \\
\text { fibres }\end{array}$ \\
\hline $\begin{array}{l}\text { Clinical symptoms of a myopathy } \\
\text { Clinical signs of a myopathy }\end{array}$ & $\begin{array}{l}\overline{\mathbf{c}} \\
\mathbf{P} \\
\overline{\mathbf{c}} \\
\mathbf{P}\end{array}$ & $\begin{array}{r}0.62 \\
<0.05 \\
0.57 \\
<0.05\end{array}$ & $\begin{array}{r}0.50 \\
<0.01 \\
0.27 \\
>0.05\end{array}$ & $\begin{array}{r}0.41 \\
<0.01 \\
0.06 \\
>0.05\end{array}$ & $\begin{array}{r}0.51 \\
<0.01 \\
0.14 \\
>0.05\end{array}$ & $\begin{array}{r}0.09 \\
>0.05 \\
0.33 \\
<0.05\end{array}$ & $\begin{array}{r}0.09 \\
>0.05 \\
0.33 \\
<0.05\end{array}$ & $\begin{array}{r}0.42 \\
<0.01 \\
0.30 \\
<0.50\end{array}$ & $\begin{array}{r}0.47 \\
<0.01 \\
0.34 \\
<0.05\end{array}$ & $\begin{array}{r}0.35 \\
<0.05 \\
0.49 \\
<0.01\end{array}$ & $\begin{array}{r}0.39 \\
<0.01 \\
0.55 \\
<0.01\end{array}$ & $\begin{array}{r}0.27 \\
0.06 \\
0.46 \\
<0.01\end{array}$ \\
\hline & $\mathbf{n}$ & 8 & 16 & 16 & 16 & 18 & 18 & 17 & 16 & 19 & 18 & 18 \\
\hline
\end{tabular}


possible to assess the response to treatment since the majority of patients recover within three months of therapy, although in occasional cases response can be delayed and require additional treatment (Fessel, 1968). Although an increased number of central nuclei is a non-specific change, it is of interest that it may be produced in response to a specific altered endocrine environment, since it was found in hypothyroid but not hyperthyroid myopathy (unpublished observations). The preferential involvement of type II fibres, with elevated central nuclear counts and an associated atrophy and loss, suggests a relatively specific metabolic injury to this fibre in hypothyroid myopathy, as we have argued previously (McKeran et al., 1975). Further attention to the specificity of fibre involvement in central migration of nuclei may suggest a hitherto unsuspected selective muscle fibre type damage in other myopathies.

In the present study, the biochemical evidence of hypothyroidism was related to the severity of the myopathic symptoms and signs before treatment (Table 1). Patient 7 was an exception, possibly because the severity of a proximal myopathy may depend on both the degree and duration of biochemical hypothyroidism, and in that patient the metabolic challenge may not have been prolonged. Indirect support for this concept was obtained in the present investigation by the fact that during treatment with L-thyroxine the biochemical parameters, including serum CPK, had returned to normal values before the proximal myopathy had recovered or the muscle tissue abnormalities had returned to normal (Table 1, patients 1 and 2).

There is, unfortunately, no accurate way at present to estimate the duration of severe hypothyroidism. It is possible that the histological parameters of muscle fibre type percentages, median diameter, and increased central nuclear counts may reflect the duration of hypothyroidism since the greatest abnormality was found in the most severely clinically affected patients and they took the longest to recover (Table 1).

The myopathic symptoms and signs before and during treatment were correlated with the extent of a type II fibre atrophy and increased central nuclei (Table 2). The myopathic signs were also related to a type II fibre loss, but the myopathic symptoms were not. The myopathic symptoms were related in severity to the biochemical measures of hypothyroidism. Myopathic signs were not related to any of these measures except the TSH (Table 2). CPK values returned to normal within one month of treatment in all patients except patient 5 , who failed to take her tablets regularly (Table 1). Thus the return of CPK levels to normal cannot be used as a reliable biochemical marker of the rate of recovery of a proximal myopathy in hypothyroidism. A similar situation is encountered in patients with polymyositis treated with steroids, when the ESR and serum CPK values may be normal when there is still marked clinical weakness and abnormalities on muscle biopsy. The present study emphasises the interest attached to muscle fibre percentage and diameter measurements with central nuclear counts as histological parameters of improvement, since they were correlated with the rate of clinical improvement and may therefore provide an additional method of assessing the response to treatment in hypothyroid and possibly other types of myopathy.

\section{References}

Adams, R. D., Denny-Brown, D., and Pearson, C. M. (1953). Diseases of Muscle, p. 17. Hoeber, New York.

Baker, W. De C., Morgan, G., and Stark, A. (1973). Central nuclear counting in detection of carriers of Duchenne type muscular dystrophy. In Clinical Studies in Myology: Proceedings of the 2nd International Congress on Muscle Diseases, 1971, Pt. 2 (International Congress Series, 295), edited by B. A. Kakulas, pp. 648652. Excerpta Medica, Amsterdam.

Bethlem, J., Van Wijngaarden, G. K., Meijer, A. E. F. H., and Hülsmann, W. C. (1969). Neuromuscular disease with type I fibre atrophy, central nuclei, and myotobelike structures. Neurology, 19, 705-710.

Brooke, M. H., and Engel, W. K. (1966). The histological diagnosis of neuromuscular diseases, a review of 79 biopsies. Archives of Physical Medicine and Rehabilitation, 47, 99-121.

Brooke, M. H., and Engel, W. K. (1969a). The histographic analysis of human muscle biopsies with regard to fibre types. I. Adult male and female. Neurology, 19, 221-223.

Brooke, M.H., and Engel, W.K.(1969b). The histographic analysis of human muscle biopsies with regard to fibre types. II. Diseases of the upper and lower motor neuron. Neurology, 19, 378-393.

Dubowitz, V., and Brooke, M. H. (1973). Muscle Biopsy: A Modern Approach. W. B. Saunders, London.

Edwards, R. H. T. (1971). Percutaneous needle-biopsy of skeletal muscle in diagnosis and research. Lancet, 11, 593-596.

Engel, W. K., Gold, G. N., and Karpati, G. (1968). Type I fibre hypotrophy and central nuclei. A rare congenital muscle abnormality with a possible experimental model. Archives of Neurology, 18, 435-444.

Fenichel, G. M. (1969). Abnormalities of skeletal muscle maturation in brain damaged children: A histochemical study. Developmental Medicine and Child Neurology, 9, 419-426.

Fessel,W. J. (1968). Myopathy of hypothyroidism. Annals of Rheumatic Diseases, 27, 590-596.

Greenfield, J. G., Shy, G. M., Alvord, E. C., and Berg, L. (1957). An Atlas of Muscle Pathology in Neuromuscular Diseases. Livingstone, Edinburgh and London. 
McKeran, R. O., Slavin, G., Andrews, T. M., Ward, P., and Mair, W. G. P. (1975). Muscle fibre type changes in hypothyroid myopathy. Journal of Clinical Pathology, 28, 659-663.

Medical Research Council (1943). Aids to the Investigation of Peripheral Nerve Injuries (War Memoranda, No. 7), revised 2nd edition. HMSO, London.

Padykula, H. A., and Herman, E. (1955). The specificity of the histochemical method for adenosine triphosphatase. Journal of Histochemistry and Cytochemistry, 3, 170-183.
Ramsay, I. (1974). Thyroid Disease and Muscle Dysfunction. Heinemann, London.

Sher, J. H., Rimalovski, A. B., Athanassiades, T. J., and Aronson, S. M. (1967). Familial centronuclear myopathy. Neurology, 17, 727-742.

Spiro, A. J., Shy, G. M., and Gonatas, N. K. (1966). Myotubular myopathy. Archives of Neurology, 14, 1-14.

Requests for reprints to: Dr R. O. McKeran, Division of Inherited Metabolic Diseases, Clinical Research Centre, Watford Road, Harrow, Middlesex, HA1 3UJ, UK. 